\title{
Formulation development and establishment of quality standards of sedative drug "Flegmen"
}

\author{
Zaynab Sidametova*, Ne'mat Olimov
}

Department of Pharmacology, Tashkent Parmaceuticals Institute, Tashkent, Uzbekistan

Received: 19 February 2017

Revised: 21 March 2017

Accepted: 28 March 2017

\section{*Correspondence to:}

Dr. Zaynab Sidametova, Email: author.uzb@mail.ru

Copyright: (C) the author(s), publisher and licensee Medip Academy. This is an openaccess article distributed under the terms of the Creative Commons Attribution NonCommercial License, which permits unrestricted noncommercial use, distribution, and reproduction in any medium, provided the original work is properly cited.

\begin{abstract}
Background: Sedatives have long been widely used in all sectors of traditional and folk medicine (stress - sensitive patients with neurasthenia, neurosis, anxiety - depressive states, irritability, sleep disorders, emotional disorders, etc.). The objectives of this study were to determine the quantitative content of flavonoids in the collection of "Flegmen".

Methods: As raw materials use the herb of Jerusalem sage Regel (Herba phlomis Regelii) - 30 pieces; Turkestan motherwort grass (Herba Leonuri turkestanicae) - 30 pieces; licorice root (Radix Glycyrrhizae) - 20 parts; peppermint leaves (Folia Mentha piperite) - 20 pieces. All components of sedative collection are grown in Uzbekistan and have sufficient natural stock. The loss in weight upon drying were made in the range of 8.41 to $9.67 \%$; ash shared from 7.9 to $8.73 \%$; ash insoluble in $10 \%, \mathrm{HCl}$ from 2.0 to 2.32 ; Particles not passing through a sieve with hole diameter of $7 \mathrm{~mm}$ from 5.1 to 7.5. Particles passing through a sieve with a hole diameter of $0.5 \mathrm{~mm}$, from 2.8 to 3.2 percent. Particles of raw materials, loss of natural color from 1.7 to 2.4 percent. Organic impurity ranged from 1.1 to $1.32 \%$; mineral admixture is 0.4 to $0.9 \%$.

Results: The content of flavonoids sedative collection "Flegmen" in the range of 0.88-0.9 percent. Based on these data, the rate of content of flavonoids in the collection set at least $0.4 \%$. In order to determine the period of validity of sedative collection "Flegmen", the storage stability and optimum expiration date were studied. New sedative collection "Flegmen" consists exclusively of local official medicinal plants with sufficient natural reserves. The expiration date of the licorice roots is 4 years, for herb of Jerusalem sage Regel and motherwort is 3 years, and for peppermint leaves, it is 2 years. For establishing expiry date of studied collection, five batches of laboratory sample of the drug were prepared, packed according to project temporary pharmacopeia article (TPA).

Conclusions: According to the results of commodity and chemical study of the collection, the characteristics of its authenticity and quality. To determine the expiry date, the stability during storage of the studied collection and the optimum shelf life for 2 years. Vegetable collection "Flegmen" is recommended for use in medical practice as a sedative for central nervous system diseases (neurosis, migraine, neurasthenia, insomnia, etc.).
\end{abstract}

Keywords: Characteristics of authenticity, Medicinal plants, Pharmacological screening, Quantification, Sedatives fees, Standardisation

\section{INTRODUCTION}

Sedatives have long been widely used in all sectors of traditional and folk medicine (stress - sensitive patients with neurasthenia, neurosis, anxiety - depressive states, irritability, sleep disorders, emotional disorders, etc.).
In the modern rhythm of life, everyone without sedatives, to cope not. Normal functions of the nervous system is great importance for all systems and organs of our body. Today it is not customary to put your emotions out in the world, but rather had to suppress it all inside. Forced suppression of natural reaction is visceral, so modern 
people cannot be peace without sedatives. The interests are increased on the part of doctors and patients due to the possibility of self-medication, ease of application, ease of dose, a minimum of contraindications and side effects. These properties are due to, primarily, of vegetable origin of most components, relatively low concentration of active substances (a complex of sedative drugs), which virtually eliminates the possibility of overdose, as well as a wide range of indications for their use: vegetarians, neurosis with phobic disorders, trouble falling asleep, anxiety, neurasthenia, etc. ${ }^{1}$ In this regard, relevant is the creation of new medicinal fee on the basis of local vegetable raw materials. Modern studies have shown that the composition fees due to the interaction of medicinal plants can more fully demonstrate the pharmacologic action while limiting its toxicity. A phenomenon in which there is a symbiotic action of biologically active substances of one or more plants is called photokinetic synergy. It is also believed that from the variety of biologically active substances (BAS) of various plants included in the collection, the body has the ability through self-regulation to select for the missing components and include them in the processes of exchange. The therapeutic efficacy of fees is a manifestation of the general laws of the synergies of existing and related substances, summation and potentiation of their pharmacological effects. $^{2}$

\section{METHODS}

The development of new sedative composition of the collection and further on its basis of new, highly effective drugs sedation quite relevant. ${ }^{3-5}$ To achieve this goal, the number of medicinal plants most commonly used in the formulation of sedatives and having sufficient natural resources were compiled sedation fees.

For the study, we selected 10 different kinds of raw materials, which is grown in the Republic of Latvia; the most commonly used in the formulation of sedatives and sufficient commercial reserves have yet in the country. The compositions of the four recommended sedative fees were subject pharmacognosy quality of analysis according to the requirements of GF XI and pharmacological screening test on the subject of sedation. Pharmacological studies of the proposed collection were conducted on laboratory white mice of both sexes, weighing 19 to $21 \mathrm{~g}$.

The research was conducted at the Department of Pharmacology and Clinical Pharmacy, Tashkent Pharmaceutical Institute, under the direction of Professor Aliev H.U. The results of the research showed that the most pronounced sedative activity had a drug collection no. 3, called by us "Flegmen".

Part of the collection includes a new medicinal plant Jerusalem sage Regel, which belongs to the family Lamiaceae. It is a perennial herbaceous plant. As raw materials use the herb of Jerusalem sage Regel (Herba phlomis Regelii) - 30 pieces; Turkestan motherwort grass (Herba Leonuri turkestanicae) - 30 pieces; licorice root (Radix Glycyrrhizae) - 20 parts; peppermint leaves (Folia Mentha piperite) - 20 pieces. All components of sedative collection are grown in Uzbekistan and have sufficient natural stock.

The Jerusalem sage Regel - a new medicinal plant used for conditions of increased excitability of the central nervous system: neurosis, epilepsy, nervous insomnia, as a sedative in hypertension. In Central Asia, there is widespread in the Western Tien Shan, and it dominates in the lower part of the upper band of hills, Chirchik-Angren Rivers on the Northern slopes.

According to the research and literature, Jerusalem sage Regel contains flavonoids, rutin, hyperoside - $4.50 \%$, tannins (polyphenols titrated) - $2.30 \%$, essential oil $0.1 \%$, resinous substances $(\beta$ - sitosterol and ursolic acid) - $3.32 \%$, anthocyanins, cyanine and pelargonin $-0.43 \%$, phenolic acids are $3.2 \%$, coumarins (xanthotoxin) $0.42 \%$, iridoids (harpagide and harpagide-8-acetate) $5.15 \%$, carotenoids - $0.13 \%$, ascorbic acid - $0.055 \%$, organic acids - $1.76 \%$, phenol carbonic acids (coffee, chlorgen, rosemary, 1-coffeil quinic acid) $-1.35 \%$, sugars (galactose, glucose, fructose, rhamnose) $-4.34 \%$.

This collection is a mixture of medicinal - plant raw materials of various shapes, consisting of roots, stems, leaves, flowers and unripened fruit residue. Colour collection bright green, the smell of weak, specific, flavour - sweet, slightly chilling.

To establish high quality of the collection was determined by the following numerical indicators: loss in weight when absolutely dried, the content of total ash and ash insoluble in $10 \%$ hydrochloric acid, organic and mineral impurities, and the content of biologically active substances.

Numeric collection rates were determined in five batches of the collection according to methods specified in the relevant ND. ${ }^{6}$ As impurities in the collection was determined by a measure of "particles of raw materials, loss of natural colour". Our experiments show that the components of the collection when grinding to a particle size from 0.5 to $7.0 \mathrm{~mm}$ distributed relatively evenly collection, which is an important factor in proper dosing of the drug.

The loss in weight upon drying were made in the range of 8.41 to $9.67 \%$; ash shared from 7.9 to $8.73 \%$; ash insoluble in $10 \%, \mathrm{HCl}$ from 2.0 to 2.32; Particles not passing through a sieve with hole diameter of $7 \mathrm{~mm}$ from 5.1 to 7.5 . Particles passing through a sieve with a hole diameter of $0.5 \mathrm{~mm}$, from 2.8 to 3.2 percent. Particles of raw materials, loss of natural color from 1.7 to 2.4 percent. Organic impurity ranged from 1.1 to $1.32 \%$; mineral admixture is 0.4 to $0.9 \%$. 
On the basis of commodity and chemical analysis standards are numeric parameters, determining high quality of the studied collection. Thus, the moisture content of the fee should be no more than $13.0 \%$, total ash - no more than $10.0 \%$. Ash insoluble in $10 \%$, hydrochloric acid - no more than $3.0 \%$, particles of raw materials, change of natural color - no more than $3.0 \%$. Particles of raw material passing through a sieve with a hole diameter of $7 \mathrm{~mm}$, it is no more than $10.0 \%$, particles of raw material passing through a sieve with holes' diameter of $0.5 \mathrm{~mm}$ to no more than $4.0 \%$, an organic impurity is no more than $2.0 \%$, mineral impurity is no more than $1.0 \%$.

When developing methods of standardization of collection came from the fact that its pharmacological effect due to the complex of biologically active substances contained in the individual components of collection, primarily flavonoids, saponins and essential oils. Given this fact, as well as the literature data on physiological properties of flavonoids, saponins and essential oils - these groups of biologically active substances were selected as a criterion of the high-quality collection.

To establish the authenticity of the collection is the following qualitative reactions:

- About $1 \mathrm{~g}$ of the minced collection were boiled for 5 min with $20 \mathrm{ml} \mathrm{50 \%} \mathrm{ethanol,} \mathrm{and} \mathrm{filtered} \mathrm{through} \mathrm{a}$ paper filter. $1 \mathrm{ml}$ of filtrate was added $2 \mathrm{ml} 2 \%$ solution of aluminium chloride in $95 \%$ ethanol and 7 $\mathrm{ml}$ of $95 \%$ ethanol, the solution becomes greenish yellow colour (flavonoids).

- On the start line of the chromatographic plate, "Silica gel 60/254" size $13 \mathrm{~cm}$ x $5 \mathrm{~cm}$ pipette was applied $0.01 \mathrm{ml}$ of the alcoholic extract. In parallel, with a distance of $2 \mathrm{~cm}$ from the test sample, $0.01 \mathrm{ml} 0.5 \%$ solution of menthol in $95 \%$ alcohol is applied (to check the suitability of chromatographic system). Plate with applied samples was air dried for 3-5 minutes, then placed in a camera with the solvent of chloroform-benzene $(3: 1)$. When the solvent front reached $10 \mathrm{~cm}$ plates, they were pulling it from the chamber, dried on air for 2-3 minutes (before the elimination of a smell of solvents), and sprayed with a solution of vanillin $(0.2 \mathrm{~g}$ vanillin in $10 \mathrm{ml}$ of concentrated sulfuric acid). Next, the plate was placed in a drying Cabinet at $105^{\circ} \mathrm{C}$. The chromatogram of the test solution showed a single spot of purple - red colour on the level of spot chromatograms of a solution of menthol (menthol).

- On the line of chromatographic platelets "Silicagel 60/254", size $13 \mathrm{~cm}$ x $5 \mathrm{~cm}$ pipette was applied 0.01 $\mathrm{ml}$ of alcoholic extract. As a witness, $0.01 \mathrm{ml}$ of $0.5 \%$ solution of glycyrrhizic acid in $95 \%$ alcohol was applied. Plate with applied samples was air dried for 3-5 minutes, then placed in a chamber with the solvent system chloroform - acetic acid (ratio 1:1). When the solvent front reached $10 \mathrm{~cm}$ plates, they were pulling from the chamber, and dried in air for 2-3 minutes (before the elimination of solvents smell), and sprayed with a solution of vanillin $(0.2 \mathrm{~g}$ vanillin in $10 \mathrm{ml}$ of concentrated sulfuric acid) until the yellow spots (saponins).

On the chromatogram, tested solution showed a single spot of yellow colour on the level of spot chromatograms of a solution of witness (glycyrrhizic acid).

The aim of our further studies was to determine the quantitative content of flavonoids in the collection of "Flegmen". Drugs of vegetable origin, usually standardization of biologically active substances, the content of which determines the therapeutic effect of the herbal mixture. In the standardization of the studied collection "Flegmen", we followed the principle of "passthrough" standardization, ensuring unification of performance standards and methods of quality assessment in a number of raw materials, collect finished dosage form. The main components of the studied collection are standardized on a content of total flavonoids, which determine their therapeutic effect. Therefore, development of quantitative method determination used the spectrophotometric method after reaction with a solution $\mathrm{AlCl}_{3}$ at a wavelength of $430 \mathrm{~nm}$ in terms of quercetin.

For this analytical test, raw material was milled to a particle size passing through a sieve with holes of $1 \mathrm{~mm}$ diameter. Approximately $1 \mathrm{~g}$ (exact amount) of the crushed material was placed in a flask with a ground joint and a capacity of $150 \mathrm{ml}$, added $30 \mathrm{ml}$ of $50 \%$ alcohol. The flask was attached to reverse refrigerator, and heated on boiling water bath for 30 minutes, periodically shaking to remove particles of raw materials from the walls. Hot extract was filtered through cotton wool into a measuring flask with the volume capacity of $100 \mathrm{ml}$, so that the raw material particles falling on the filter. Cotton wool was placed in a flask for extraction and added $30 \mathrm{ml}$ of $50 \%$ alcohol. The extraction was repeated twice, in the conditions described above, filtering the extract into the same measuring flask. After cooling, the extract volume was brought to $50 \%$ alcohol up to the mark and mixed (solution A).

In a volumetric flask with a capacity of $25 \mathrm{ml}$ was placed $1.0 \mathrm{ml}$ of solution $\mathrm{A}$ and $1 \mathrm{ml}$ of $1 \%$ solution of aluminium chloride in $95 \%$ alcohol, and brought the volume of solution $95 \%$ alcohol to the label. After 40 minutes measured optical density of the solution on the spectrophotometer at a wavelength of $430 \mathrm{~nm}$ in a cuvette with a layer thickness of $10 \mathrm{~mm}$. as a solution comparison solution was used, consisting of $1.0 \mathrm{ml}$ of extract, 1 drop of diluted acetic acid and brought to $95 \%$ alcohol to the mark in a volumetric flask with capacity of $25 \mathrm{ml}$.

In parallel, we measured the optical density of the solution - State standard sample (SSS) of quercetin, 
prepared analogously to the test solution. The sum of flavonoids in terms of quercetin and dry raw materials in percentage $(\mathrm{X})$ was calculated by this formula:

$$
X=\frac{D \cdot m_{0} \cdot 5 \cdot 100 \cdot 100 \cdot 100}{D_{0} \cdot m \cdot 100 \cdot 25(100-W)}
$$

where D - optical density of test solution; D0 - optical density of the solution of quercetin bonds; m - mass of raw material, $\mathrm{g}$ and $\mathrm{m} 0$ mass of SSS quercetin, gram; W loss in weight when drying raw, $\%$.

\section{RESULTS}

The results of quantitative determination of flavonoids and their metrological characteristics are presented in Table 1.

Table 1: The results of quantitative determination of flavonoids in sedative collection "Flegmen".

\begin{tabular}{|c|c|c|c|c|c|}
\hline $\mathbf{X}_{\mathbf{i}}$ & f & $\mathbf{X}_{\mathrm{cp}}$ & $\mathbf{d}_{\mathbf{i}}$ & $\mathbf{d}_{\mathbf{i}}^{2}$ & The metrological characteristics \\
\hline 0,883 & \multirow{5}{*}{4} & \multirow{5}{*}{0,892} & $-0,0092$ & 0,000085 & \multirow{5}{*}{$\begin{array}{l}P=95 \% ; t(P, f)=2,78 ; \\
S^{2}=0,000049 ; S_{x} c p=0,0031 ; \\
\Delta X=0,0195 ; \Delta X c p=0,0087 \\
\varepsilon=2,18 ; \varepsilon=0,97\end{array}$} \\
\hline 0,889 & & & $-0,0032$ & 0,000010 & \\
\hline 0,891 & & & $-0,0012$ & 0,000001 & \\
\hline 0,897 & & & 0,0048 & 0,000023 & \\
\hline 0,901 & & & 0,0088 & 0,000077 & \\
\hline
\end{tabular}

As can be seen from Table 1, the content of flavonoids sedative collection "Flegmen" in the range of $0.88-0.9$ percent. Based on these data, the rate of content of flavonoids in the collection set at least $0.4 \%$.

In order to determine the period of validity of sedative collection "Flegmen", the storage stability and optimum expiration date were studied. ${ }^{6,7}$ New sedative collection "Flegmen" consists exclusively of local official medicinal plants with sufficient natural reserves. The expiration date of the licorice roots is 4 years, for herb of Jerusalem sage Regel and motherwort is 3 years, and for peppermint leaves, it is 2 years. For establishing expiry date of studied collection, five batches of laboratory sample of the drug were prepared, packed according to project Temporary Pharmacopeia Article (TPA). The collection was packaged in $50 \mathrm{~g}$ packs of cardboard from a cardboard box, type chrome-ersatz and $1.5 \mathrm{~g}$ filter bags for one-time welding of paper filter for 25 pieces and placed in packs of cardboard, leaving, their storage in natural conditions in a dry, dark place. Test samples of drugs were examined for purity by numeric indicators and the quantitative content of flavonoids. The content of flavonoids was determined by the above-described spectrophotometric method.

The results of the commodity analysis 5 parties collection showed that within 2 years the main numeric indicators of the investigated series of charges did not change significantly.

Proceeding from this, we can conclude that the optimum shelf life of sedative collection "Flegmen" based on the data of commodity and chemical analyses. Revealed that the collection "Flegmen" at the observance of conditions of storage stands the test for the content of active ingredients (not less than $0.4 \%$ flavonoids calculated as quercetin) for 2 years.

\section{DISCUSSION}

It is illustrated that the analysis of the obtained data testifies to positive dynamics of the clinical condition of patients in all groups. Negative impact of sedation on indicators of hemoglobin, erythrocytes, erythrocyte sedimentation rate and leukogram are not installed. There are also no reliable oscillations of bilirubin, aminotransferases in the blood, which indicates the safety of the drug and the absence of negative hepatotropic effects. Side effects when you use is not fixed. ${ }^{8}$ This article presents a comparative evaluation of efficacy and tolerability of a treated with sedative drug - "Flegmen" produced by "SORB-TECH", Uzbekistan, and patients taking traditional basic therapy. Clinical trials showed that utilizing the drug "sedative drug Flegmen" produced by "SORB-TECH", Uzbekistan in the complex treatment of patients with syndrome of vegetative dystonia, improves clinical status, general well-being and disappearance of irritability, nervousness and improve sleep patients. The sedative drug "Flegmen" is well tolerated by patients in clinical trials, adverse reactions were identified. Sedative drug "Flegmen" is an effective sedative drug, well tolerated, and fully comparable with other sedative drugs. Further, the fact that this drug is the development of Tashkent Pharmaceutics Medical Institute permitted for clinical use and registered in the Republic of Uzbekistan, on the basis of positive clinical trial results from 3 clinical centers. Currently LLC "Sorb-tex" Uzbekistan plans to produce sedative drug "Flegmen" based on "guidance on conducting clinical trials and examination of materials" (order of the MOH of Republic of Uzbekistan No. 334, dated 25.07.2001) registration of the drug will be carried out on the basis of limited clinical trials. ${ }^{9}$ 


\section{CONCLUSION}

The results of a pharmacological screening test on the subject of sedation, a sedative created a new collection "Flegmen", as mentioned above consists of exclusively local official medicinal plants, which have sufficient natural stock. It is determined by its specific pharmacological activity, and quantitative content of flavonoids. According to the results of commodity and chemical study of the collection, the characteristics of its authenticity and quality. To determine the expiry date, the stability during storage of the studied collection and the optimum shelf life for 2 years. Vegetable collection "Flegmen" is recommended for use in medical practice as a sedative for central nervous system diseases (neurosis, migraine, neurasthenia, insomnia, etc.).

\section{ACKNOWLEDGEMENTS}

Authors would like to thanks Tashkent Pharmaceutical Institute; Tashkent Medical Academy II clinic, Tashkent, Republic of Uzbekistan. We also thank junior researcher Bekhzod Abdullaev for his help in initiating the study.

Funding: No funding sources

Conflict of interest: None declared

Ethical approval: The study was approved by the Institutional Ethics Committee

\section{REFERENCES}

1. Karimov SI. Sedatives of plant origin. C. I. Karimov Pharmacy. 1999;4:26.
2. Koroleva LR, Pokrovskaya AV. Herbal medicine with neurotic disorders. Text, Russian Med J. 2004;4:26-9.

3. Maravina IN, Yatsuk VY, Eletskaya OA. The study in the development of herbal medicines from charges. Pharma. 1998;6:13-4.

4. Markaryan AA. Basic principles of preparation and standardization of a comprehensive means of plant origin. Problems of Health Management. 2003;6:7881.

5. Marchenko LG, Pastushenkov LV, Sinev YN. Medicinal plant gathering. Saint-Petersburg Chemical-Pharmaceutical Institute; 1991:46.

6. Meshkovsky AP. Testing of stability and establishment of expiration dates of drugs. Farmateka. Moscow. 2000;2:20-30.

7. Zeigarnik M, Alekseev MI. Sedatives of plant origin is available and safe. Remedium. 2000;9:85-6.

8. Salamatova ZE, Ganiev AK, Tulyaganov DK. Clinical studies sedative collection "Flegmen". Materials of scientific-practical conference "Integration of education, science and production in pharmacy". Tashkent. 2011:411.

9. Salamatova ZE, Aliev HU, Ganiev AK. Study of pharmacology of sedative collection "Flegmen". Pharma J Toshkent. 2007;1:75-7.

Cite this article as: Sidametova Z, Olimov N. Formulation development and establishment of quality standards of sedative drug "Flegmen". Int J Basic Clin Pharmacol 2017;6:1090-4. 